\title{
MicroRNA-205 promotes the tumorigenesis of nasopharyngeal carcinoma through targeting tumor protein p53-inducible nuclear protein 1
}

\author{
GUOHUI NIE ${ }^{1}$, HONGFANG DUAN ${ }^{1,2}$, XIAOQING LI $^{3,4}$, ZHENDONG YU ${ }^{5}$, \\ LIANG LUO ${ }^{1,2}$, RUIJING LU ${ }^{3,4}$, ZILIANG JI ${ }^{4}$ and WEI ZHANG ${ }^{6}$ \\ ${ }^{1}$ Department of Otolaryngology, Peking University Shenzhen Hospital, Shenzhen, Guangdong 518036; \\ ${ }^{2}$ Department of Clinical Medicine, Guangzhou Medical University, Guangzhou, Guangdong 510000; \\ ${ }^{3}$ Department of Clinical Laboratory, Peking University Shenzhen Hospital, Shenzhen, Guangdong 518036; \\ ${ }^{4}$ Department of Clinical Medicine, Shantou University Medical College, Shantou, Guangdong 515041; \\ ${ }^{5}$ Central Laboratory, Peking University Shenzhen Hospital, Shenzhen, Guangdong 518036; \\ ${ }^{6}$ Shenzhen Key Laboratory for Translational Medicine of Dermatology, Biomedical Research Institute, \\ Shenzhen Peking University - The Hong Kong University of Science and Technology Medical Center, \\ Shenzhen, Guangdong 518036, P.R. China
}

Received October 20, 2014; Accepted July 7, 2015

DOI: $10.3892 / \mathrm{mmr} .2015 .4181$

\begin{abstract}
Nasopharyngeal carcinoma (NPC) is a common type of cancer in southern China, miRNAs have been shown to be involved in the tumorigenesis of multiple cancer types. The present study aimed to explore the potential role of miR-205 in NPC. Reverse transcription quantitative polymerase chain reaction was used to determine the expression levels of miR-205 in 20 fresh NPC specimens and 20 normal nasopharyngeal tissues. The function of miR-205 in the proliferation, migration, invasion and apoptosis of NPC-derived cells was detected by MTT assay, colony formation assay, wound healing assay, Transwell assay and flow cytometry. Furthermore, a target gene of miR-205 was identified using the luciferase reporter assay. The expression of miR-205 was increased in NPC tissues compared with that in normal tissues. Overexpression of miR-205 was found to promote the proliferation, migration and invasion of NPC-derived cells,
\end{abstract}

Correspondence to: Dr Guohui Nie, Department of Otolaryngology, Peking University Shenzhen Hospital, 1120 Lianhua Road, Shenzhen, Guangdong 518036, P.R. China

E-mail:nghui@21cn.com

Dr Wei Zhang, Shenzhen Key Laboratory for Translational Medicine of Dermatology, Biomedical Research Institute, Shenzhen Peking University - The Hong Kong University of Science and Technology Medical Center, 1120 Lianhua Road, Shenzhen, Guangdong 518036, P.R. China

E-mail: zhangweispace@yeah.net

Key words: nasopharyngeal carcinoma, microRNA-205, tumor promoter, tumor protein $\mathrm{p} 53$-inducible nuclear protein 1 while apoptosis was suppressed. Tumor protein p53-inducible nuclear protein 1 was identified as a target gene of miR-205. Overall, the present study demonstrated that miR-205 may function as an oncogene in NPC tumorigenesis.

\section{Introduction}

Nasopharyngeal carcinoma (NPC) is a type of epithelial squamous cell carcinoma, which is highly malignant with local invasion and early distant metastasis $(1,2)$. Pathophysiological studies on the development of NPC have shown that genetic susceptibility, Epstein-Barr virus infection and environmental factors are the major etiological factors of NPC (3). However, the exact molecular mechanisms involved in NPC pathogenesis and progression have remained to be fully elucidated (4). In spite of the development and application of intensity-modulated radiotherapy, the treatment outcome of NPC has remained poor (5). Therefore, it is required to investigate the underlying molecular mechanisms of the progression of NPC and to identify novel molecular targets for the development of novel therapeutic strategies for NPC patients.

MicroRNAs (miRNAs), small 15-22 nucleotide non-coding RNA molecules, act as critical regulators of gene expression by binding to the 3'-untranslated region (3'-UTR) of target genes (6-8). miRNAs have important roles in cellular processes of development, differentiation, metastasis and apoptosis (9). Differential expression of miRNAs has been demonstrated in various human cancer types (10-17), including NPC (18-22). miR-205 is a highly evolutionarily conserved miRNA and was shown to be involved in tumor proliferation, apoptosis, metastasis and invasion. Of note, the expression levels of miR-205 in breast cancer, prostate cancer and laryngeal squamous cell carcinoma are consistently downregulated. However, overexpressed miR-205 promotes 
cancer cell proliferation, migration and invasion in various cancer types (23-25), including bladder cancer, endometrial carcinoma and hepatocellular carcinoma (26-28). To date, the function of miR-205 in NPC has not been fully elucidated.

The present study detected the expression of miR-205 in NPC tissues and explored the roles of miR-205 in three NPC-derived cell lines by examining its effects on the proliferation, colony formation, migration, invasion and apoptosis of these cells. Furthermore, a luciferase reporter assay was performed in order to identify a potential target of miR-205.

\section{Materials and methods}

Patients and tissue samples. All tissue samples were obtained by surgery and were quickly frozen in liquid nitrogen and stored at $-80^{\circ} \mathrm{C}$. A total of 20 fresh nasopharyngeal carcinoma specimens from NPC patients with non-keratinizing squamous cell nasopharyngeal carcinoma and no previous chemotherapy or radiotherapy prior to the surgery as well as 20 fresh normal nasopharyngeal tissues from healthy individuals who underwent nasopharyngeal endoscopy and were diagnosed as having inflammation were obtained from the Peking University Shenzhen Hospital (Shenzhen, China). The study was approved by the ethical committee of Peking University Shenzhen Hospital, and all patients provided written informed consent. The clinical tumor staging was based on the 2003 Union for International Cancer Control staging system (29). The clinicopathological characteristics of the patients are shown in Table I.

Cell culture and transfection. The human nasopharyngeal carcinoma-derived cell lines CNE2, 6-10B and 9-4E as well as the healthy human nasopharyngeal epithelial cell line NP69 were used in the present study. The cell lines used were obtained from Conservation Genetics Chinese Academy of Sciences Kunming Cell Bank (Kunming Institute of Zoology, Chinese Academy of Sciences, Kunming, Yunnan, China). The 9-4E and NP69 cells were provided by Peking University Shenzhen Hospital (Shenzhen, China), and CNE2 and 6-10B cells were a generous gift from Southern Medical University (Guangzhou, China). These cell lines were cultured in RPMI 1640 (Gibco-BRL, Invitrogen Life Technologies, Carlsbad, CA, USA) supplemented with $10 \%$ fetal bovine serum (FBS; Invitrogen Life Technologies), $1 \%$ antibiotics (100 $\mu / \mathrm{ml}$ penicillin and $100 \mathrm{mg} / \mathrm{ml}$ streptomycin sulfates; Invitrogen Life Technologies) and 1\% glutamate (Invitrogen Life Technologies) at $37^{\circ} \mathrm{C}$ in a humidified $5 \% \mathrm{CO}_{2}$ atmosphere. Transfection of miR-205 (5'-UCCUUCAUUCCACCGGAGUCUG-3') and negative control (5'-UUCUCCGAACGUGUCACGUTT) (GenePharma, Shanghai, China) were performed with Lipofectamine 2000 (Invitrogen Life Technologies), which were mixed in the Opti-MEM ${ }^{\circledR}$ I Reduced Serum medium (Invitrogen Life Technologies) following the manufacturer's instructions. Fluorescence microscopy (BX51TF; Olympus, Tokyo, Japan) was used to verify the transfection efficiency.

RNA extraction and reverse transcription quantitative polymerase chain reaction (RT- $q P C R)$. Total RNA was extracted from the clinical tissue samples by using the TRIzol reagent (Invitrogen Life Technologies) according to the manufacturer's
Table I. Clinical and pathological features of patients with nasopharyngeal carcinoma (mean age, 44 years; range, 28-61 years).

Characteristic Number of cases

Total 20

Gender

Male

16

Female

4

Degree of differentiation

Differentiated

Undifferentiated

14

Primary tumor stage

$\mathrm{T} 1$

3

$\mathrm{T} 2$

10

T3

5

T4

Union for International Cancer

Control clinical stage

I

II

III

15

IV

instructions. Reverse transcription of the extracted RNA was performed using the miScript II RT kit (Qiagen GmbH, Hilden, Germany) according to the manufacturer's instructions. PCR reactions were performed by using the miScript $S Y B R^{\circledR}$ green PCR kit (Qiagen $\mathrm{GmbH}$ ) according to the manufacturer's instructions using the Lightcycler 480 Real-Time PCR System (Roche Diagnostics, Basel, Switzerland). The reaction mixture contained: $2 \mu l \mathrm{cDNA}$ template, $2 \mu 1$ specific microRNA primer, $2 \mu 1$ 10X miScript Universal Primer, 10 $\mu 12$ X QuantiTect SYBR Green PCR Master Mix and RNase-free water was added to $20 \mu \mathrm{l}$ in total. The amplification conditions were as follows: $95^{\circ} \mathrm{C}$ for $15 \mathrm{mins}$, followed by $94^{\circ} \mathrm{C}$ for $15 \mathrm{sec}, 55^{\circ} \mathrm{C}$ for $30 \mathrm{sec}$ and $70^{\circ} \mathrm{C}$ for $30 \mathrm{sec}$, for 45 cycles. The $2^{-\Delta \Delta \mathrm{CT}}$ method was used to quantify the relative miRNA expression (30). U6 was used as an internal control for the normalization and the forward primer was 5'-ACGCAAATTCGTGAAGCGTT-3' (Invitrogen Life Technologies). The forward primer for miR-205 amplification was 5'-TCCTTCATTCCACCGGAGTCTG-3' (Invitrogen Life Technologies), and the reverse primer of U6 and miR-205 was the universal primer provided in the miScript $\mathrm{SYBR}^{\circledR}$ green PCR kit (Qiagen GmbH).

Cell proliferation assay. CNE2, 6-10B or 9-4E cells were seeded in 96 -well plates $\left(7 \times 10^{3}\right.$ cells/well). Following transfection for various time periods (0, 24, 48 and $72 \mathrm{~h}), 20 \mu \mathrm{l}$ MTT solution was added and the mixture was incubated for $4 \mathrm{~h}$ at $37^{\circ} \mathrm{C}$. Subsequently $150 \mu \mathrm{l}$ dimethylsulfoxide (Sigma-Aldrich, St. Louis, MO, USA) was added to each well followed by thorough mixing for $10 \mathrm{~min}$. The absorbance was measured using an ELISA microplate reader (680; Bio-Rad, Hercules, CA, USA) at a wavelength of $490 \mathrm{~nm}$ (with $630 \mathrm{~nm}$ as the reference wavelength). 
Colony formation assay. Following transfection for $24 \mathrm{~h}$, the cells were trypsinized and cells were seeded into six-well plates (1,000/well), cultured for 10 days, then fixed with methanol and stained with $0.1 \%$ crystal violet. Images of colonies were captured and the colonies were counted. All steps were performed in triplicate.

Analysis of apoptosis. The percentage of apoptotic cells was determined by Annexin V-fluorescein isothiocyanate (FITC)/propidium iodide (PI) staining followed by flow cytometric analysis (Gallios Flow Cytometer and Kaluza for Gallios software; Beckman Coulter, Inc., Brea, California, USA). An Annexin V/FITC Detection kit (Invitrogen, Life Technologies) was used to stain the cells following the manufacturer's instructions. A total of $2 \times 10^{5} \mathrm{CNE}-2$ or $6-10 \mathrm{~B}$ cells were seeded on six-well plates, followed by transfection and incubation for $48 \mathrm{~h}$. The cells were then washed twice with ice-cold phosphate-buffered saline, re-suspended in $1 \mathrm{X}$ binding buffer and stained with Annexin V-FITC (5 $\mu \mathrm{l})$ and PI $(3 \mu \mathrm{l})$. The experiments were repeated at least three times.

Wound-healing assay. For the wound-healing experiments, $6 \times 10^{5}$ cells were plated on six-well plates, transfected for $24 \mathrm{~h}$ and cultured for $48 \mathrm{~h}$ to confluency. A line-shaped wound was generated with a $200-\mu 1$ pipette tip, and images were captured at the 0-, 12- and 24-h time-points to measure the wound-healing distance. A DM4000B microscope (Leica, Wetzlar, Germany) was used. The migration distance $(\mu \mathrm{m})$ was assessed using MIAS-2000 software (Sichuan University, Chengdu, China). Each experiment was performed at least three times.

Cell invasion assay. Matrigel (1:5; $50 \mu \mathrm{l} /$ well; BD Biosciences, Franklin Lakes, NJ, USA) was added to Transwell chambers in a 24-well plate. Following $24 \mathrm{~h}$ of transfection, a total of $2 \times 10^{4}$ transfected CNE2, 6-10B or 9-4E cells in $100 \mu \mathrm{l}$ serum-free RPMI 1640 medium were seeded into the upper chambers (24-well insert; pore size, $8 \mu \mathrm{m}$; Corning-Costar, Corning, NY, USA), and the lower chambers were filled with $500 \mu \mathrm{l}$ RPMI 1640 medium containing 10\% FBS. After $24 \mathrm{~h}$ of incubation, the non-invaded cells on the upper side of the membrane were removed and the lower sides of the membranes were fixed with methanol, stained with $0.1 \%$ crystal violet (Sigma-Aldrich) and washed three times. Finally, the stained cells were visualized under the DM4000B microscope and manually counted. All experiments were performed in triplicate.

Luciferase reporter assay. For generating a reporter construct, the miRNA target sequences were inserted between the XhoI-NotI restriction sites in the 3'-untranslated region (UTR) of the hRluc gene of the psiCHECK ${ }^{\mathrm{TM}}-2$ luciferase vector (Promega, Madison, WI, USA). The primer sequences used for the amplification of the 3'-UTR of TP53INP1 were as follows: Forward, 5'-CGCTCGAGATTTGTTGTCTAATTA GGGGCCAAG-3' and reverse, 5-AAGGAAAAAAGCGGC CGCCAACTTCTGTAGCTTGTGAGGTACTA-3' (Invitrogen Life Technologies). Takara EmeraldAmp PCR Master Mix (Takara Bio, Inc., Otsu, Japan) was used for this assay. The reaction mixture contained: cDNA template $(2 \mu \mathrm{l})$, forward

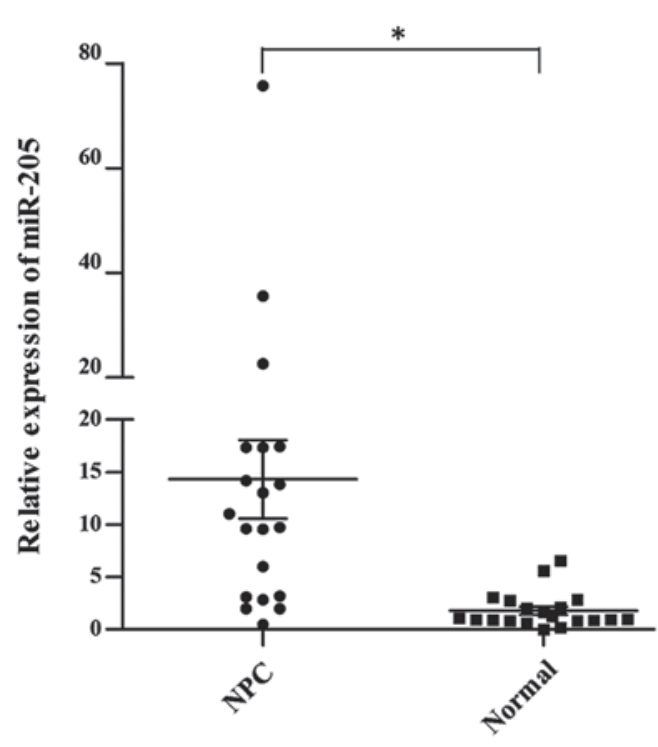

Figure 1. Expression of miR-205 in 20 NPC tissues. Reverse transcription quantitative polymerase chain reaction analysis showed that miR-205 was upregulated in NPC tissues compared with that in normal nasopharyngeal tissues $(\mathrm{P}=0.002)$. Each data-point resembles the result for one patient, horizontal lines represent their mean value and error bars represent the standard deviation. ${ }^{*} \mathrm{P}<0.05$. miR, microRNA; NPC, nasopharyngeal carcinoma.

primer $(2 \mu \mathrm{l})$, reverse primer $(2 \mu \mathrm{l})$, Master Mix $(25 \mu \mathrm{l})$, and RNase-free water $(19 \mu \mathrm{l})$. The amplification conditions were as follows: $98^{\circ} \mathrm{C}$ for 2 mins, followed by 35 cycles of $98^{\circ} \mathrm{C}$ for $10 \mathrm{sec}, 55^{\circ} \mathrm{C}$ for $39 \mathrm{sec}$ and $72^{\circ} \mathrm{C}$ for $1 \mathrm{~min}$, followed by a final extension at $72^{\circ} \mathrm{C}$ for $5 \mathrm{~min}$, then the mixture was maintained at $12^{\circ} \mathrm{C}$. The mutant construct of the $3^{\prime} \mathrm{UTR}$ was generated in the same way after substituting $\mathrm{G}$ with $\mathrm{T}$ and $\mathrm{A}$ with $\mathrm{C}$ to deactivate the potential binding sites. Co-transfection of the reporter vectors and miR-205 mimic or negative control were performed. After $48 \mathrm{~h}$, dual-luciferase activity was measured using the dual-luciferase assay system (Promega, Madison, WI, USA) according to the manufacturer's instructions. The experiments were repeated at least three times.

Bioinformatics analysis. miRWalk (http://www.umm.uniheidelberg.de/apps/zmf/mirwalk/) was used to verify the targets of miR-205. In addition to its own algorithm, miRWalk used eight additional computational algorithms - miRanda (http://www.microrna.org/microrna/home.do), miRDB (http://mirdb.org/miRDB/), RNA22 (https://cm.jefferson.edu/ rna22/), RNAhybrid (http://bibiserv.techfak.uni-bielefeld.de/ rnahybrid/submission.html), PITA (http://genie.weizmann. ac.il/pubs/mir07/mir07_prediction.html), PICTAR (http:// pictar.mdc-berlin.de/), Diana-microT (http://diana.cslab.ece. ntua.gr/microT/) and TargetScan (http://www.targetscan.org/) to predict the targets of the miRNAs.

Statistical analysis. Statistical analyses were performed using SPSS 19.0 (International Business Machines, Armonk, NY, USA). All values are expressed as the mean \pm standard deviation of results from three independent experiments. The differences were assessed using a two-tailed Student's $t$-test, while the MTT data were examined by analysis of variance. $\mathrm{P}<0.05$ was considered to indicate a statistically significant difference between values. 


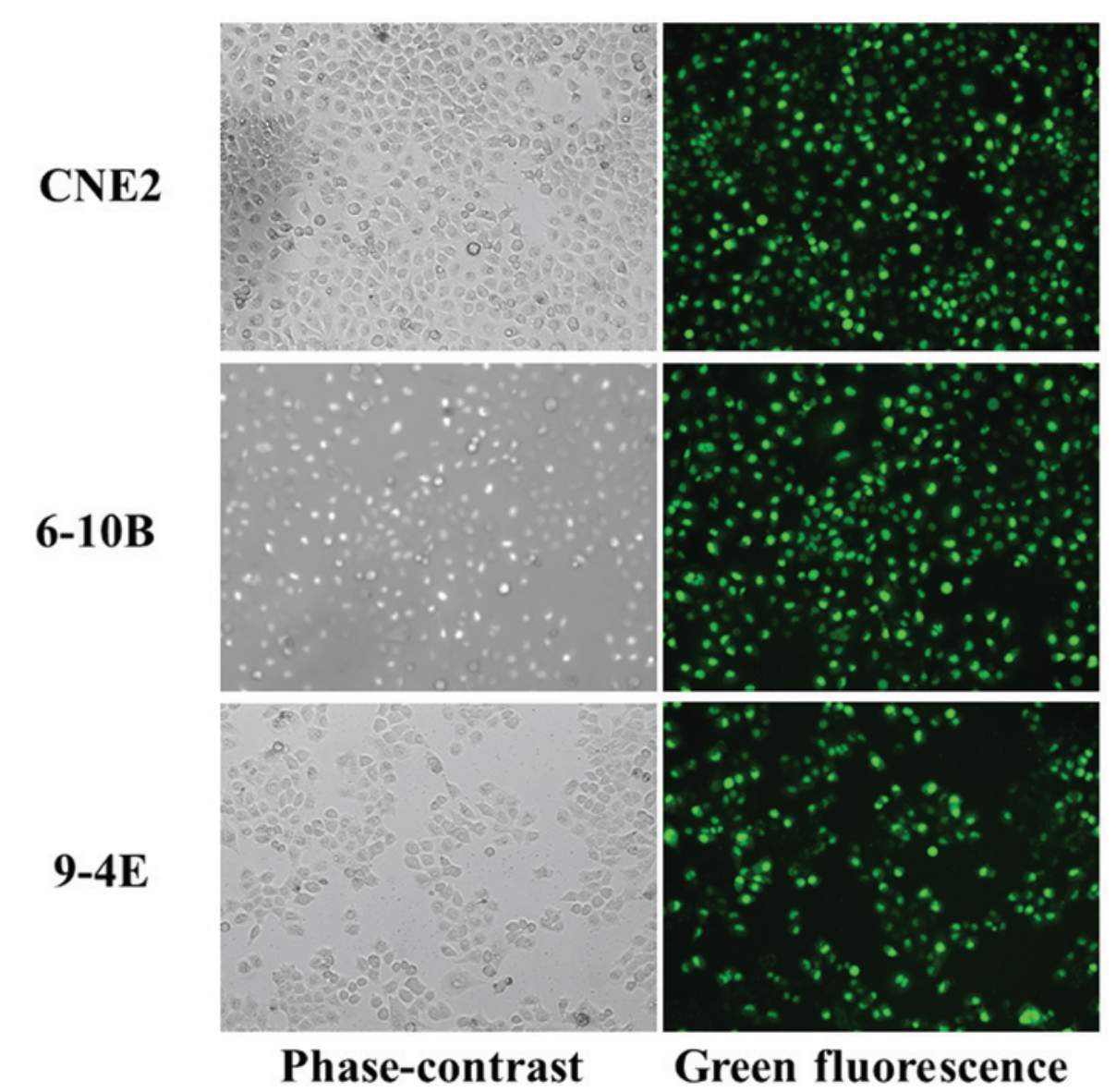

Figure 2. Transfection efficiency of three NPC-derived cells. The amount of fluorescence indicated that the efficiency was up to $90 \%$ in all of the three NPC cell lines. Magnification, x10. NPC, nasopharyngeal carcinoma.

\section{Results}

Expression of miR-205 is up-regulated in NPC tissues and enforced expression of miR-205 promotes NPC-cell growth and colony formation. As shown in Fig. 1, the expression of miR-205 was significantly upregulated in NPC tissues compared with that in the normal nasopharyngeal epithelial tissues, suggesting that overexpression of miR-205 may be important in NPC development and metastasis.

The transfection efficiency was $>90 \%$ when the cells were transfected with fluorescence-conjugated miRNAs (Fig. 2).

The MTT assay showed that the cell proliferation was significantly increased by overexpression of miR-205 in CNE2, 6-10B and 9-4E cells compared with that of the negative control cells. (Fig. 3A).

Furthermore, the effect of miR-205 on the colony formation ability of NPC cells was assessed. Overexpression of miR-205 significantly increased the colony numbers of CNE2, 6-10B and 9-4E cells (Fig. 3B). These results proved that miR-205 may act as an oncogenic miRNA in NPC and that the upregulation of miR-205 enhanced the proliferation of NPC cells.

miR-205 decreases apoptosis of NPC cells and increases $N P C$-cell migration and invasion. Flow cytometric analysis showed that overexpression of miR-205 significantly decreased the percentage of apoptotic cells in CNE2 and 6-10B cells (Fig. 4).
The wound-healing and invasion assays indicated that overexpression of miR-205 increased the rates of migration and invasion of CNE2, 6-10B and 9-4E cells compared with those of the negative control cells (Fig. 5A and B).

Tumor protein $p 53$-inducible nuclear protein 1 (TP53INP1) is a directtarget of miR-205. Bioinformatics analysis with miRWalk (http://www.umm.uni-heidelberg.de/apps/zmf/mirwalk/) was used to identify potential targets of miR-205, and from these results, TP53INP1 was selected as a potential target for further study. To verify whether miR-205 directly targets TP53INP1, dual-luciferase reporter assays were performed. The sequences of the short fragments are shown in Fig. 6A. As shown in Fig. 6B, co-transfection of CNE2, 6-10B and 9-4E cells with TP53INP1-3'UTR and miR-205 mimic caused a significant decrease in the luciferase activity compared with that of the negative control. By contrast, the activity of the reporter containing the mutated seed sequence showed no obvious change in fluorescence. This result indicated that miR-205 exerts an inhibitory effect on TP53INP1 expression via binding to the 3'-UTR of TP53INP1, and that TP53INP1 is therefore a direct target of miR-205.

\section{Discussion}

Tumorigenesis is a complex process, which is controlled by oncogenes and anti-oncogenes. Increasing evidence has 
A
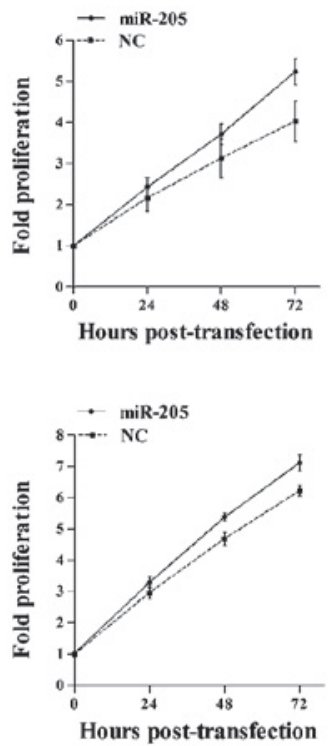

$9-4 \mathrm{E}$

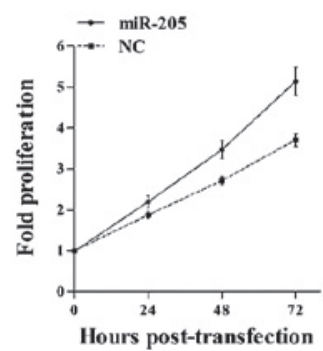

B

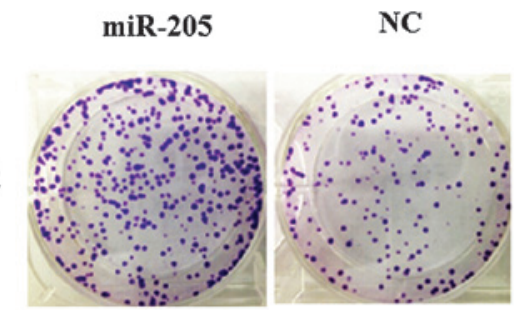

miR-205

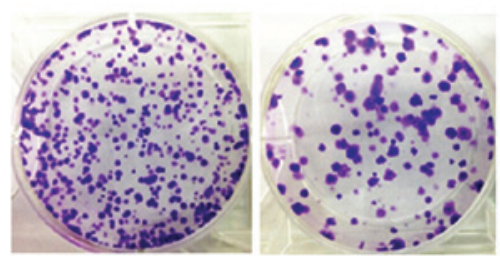

NC

$6-10 \mathrm{~B}$

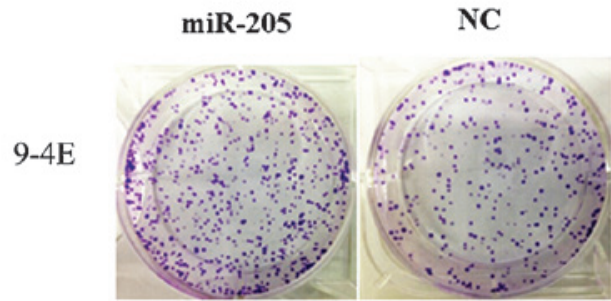

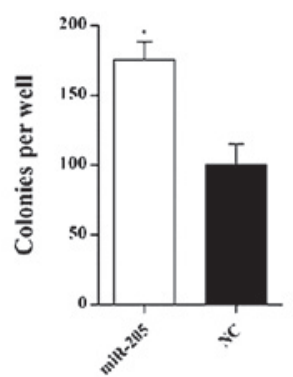
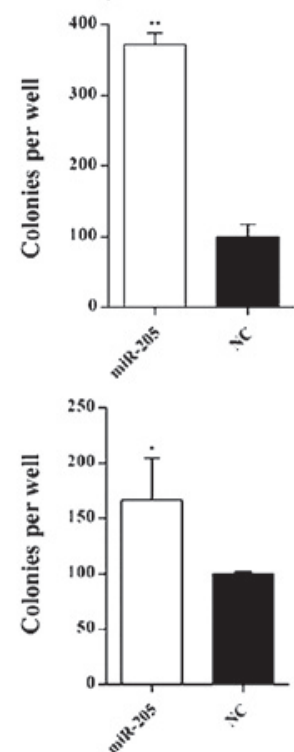

Figure 3. miR-205 promotes cell proliferation and colony formation of NPC cells. (A) The proliferation was determined using an MTT assay. The proliferation of CNE2 cells was increased by $12.5 \%(24 \mathrm{~h}), 18.6 \%(48 \mathrm{~h})$ and $29.9 \%(72 \mathrm{~h})(\mathrm{P}=0.035)$, the proliferation of 6-10B cells was increased by $11.1 \%(24 \mathrm{~h})$, $14.8 \%(48 \mathrm{~h})$ and $14.3 \%(72 \mathrm{~h})(\mathrm{P}=0.001)$ and the proliferation of 9-4E cells was increased by $17.4 \%(24 \mathrm{~h}), 27.8 \%(48 \mathrm{~h})$ and $38.6 \%(72 \mathrm{~h})(\mathrm{P}<0.001) .(\mathrm{B}) \mathrm{The}$ clonogenic potential of the cells was determined using a colony formation assay. The promotion rates of colony formation were $75.4 \%$ in $\mathrm{CNE} 2 \mathrm{cells}, 271.7 \%$ in $6-10 \mathrm{~B}$ cells and $66.9 \%$ in $9-4 \mathrm{E}$ cells. Values are expressed as the mean \pm standard deviation. ${ }^{*} \mathrm{P}<0.05,{ }^{* * *} \mathrm{P}<0.001$ vs. NC. NPC, nasopharyngeal carcinoma; miR, microRNA; NC, negative control.

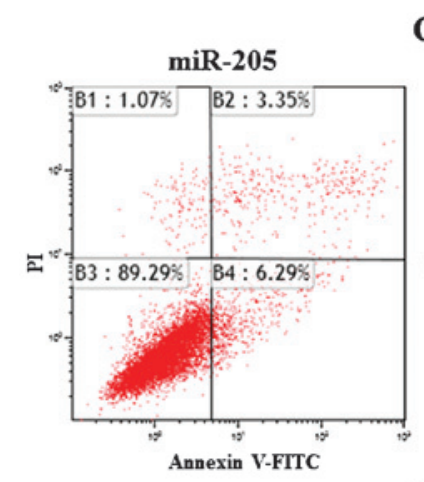

CNE2

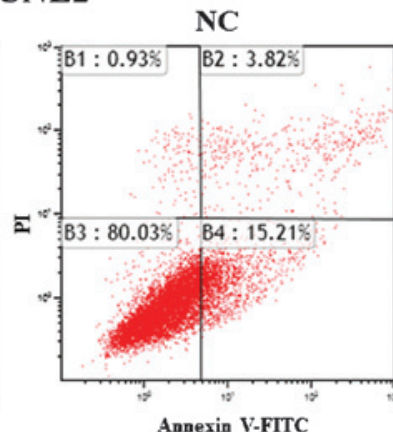

6-10B
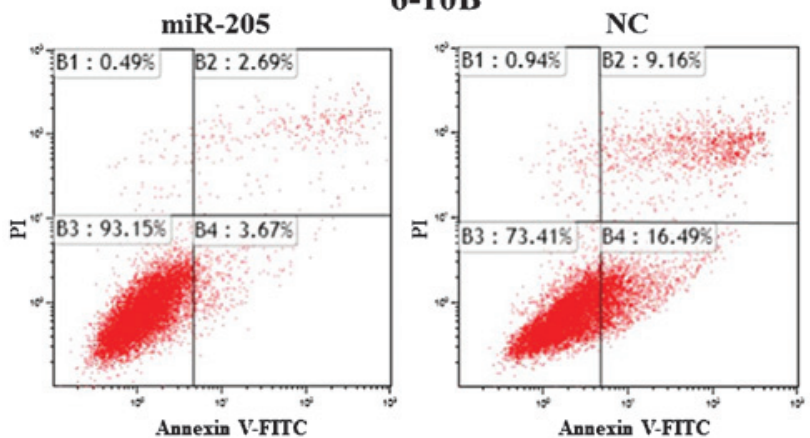

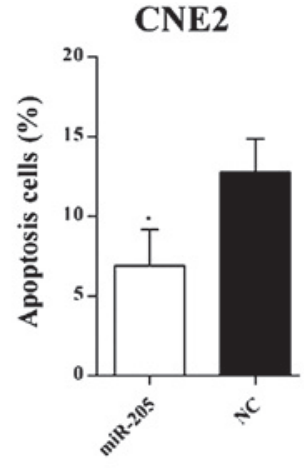

6-10B

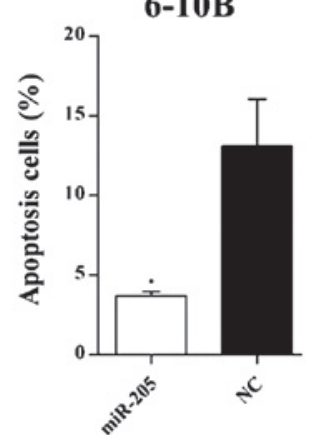

Figure 4. miR-205 affects the apoptosis of nasopharyngeal carcinoma cells. The apoptotic rate was significantly elevated (6.92 vs. 15.21\%; P=0.03) in CNE2 cells and in 6-10B cells ( 3.67 vs. $16.49 \% ; \mathrm{P}=0.005)$ following transfection with miR-205 mimic. Values are expressed as the mean \pm standard deviation. ${ }^{*} \mathrm{P}<0.05$ vs. NC. miR, microRNA; NC, negative control; PI, propidium iodide; FITC, fluorescein isothiocyanate. 
A
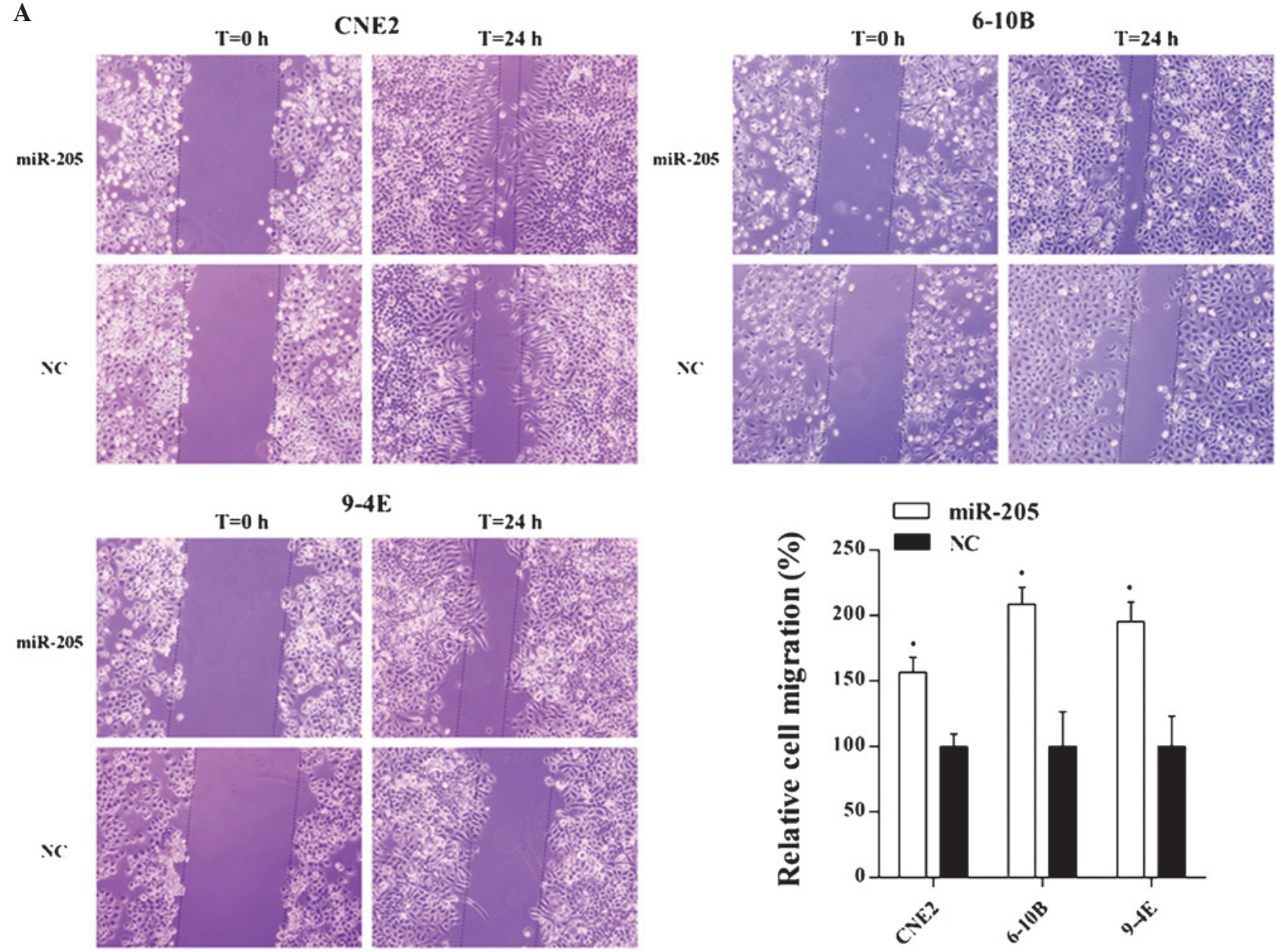

B

miR-205

NC
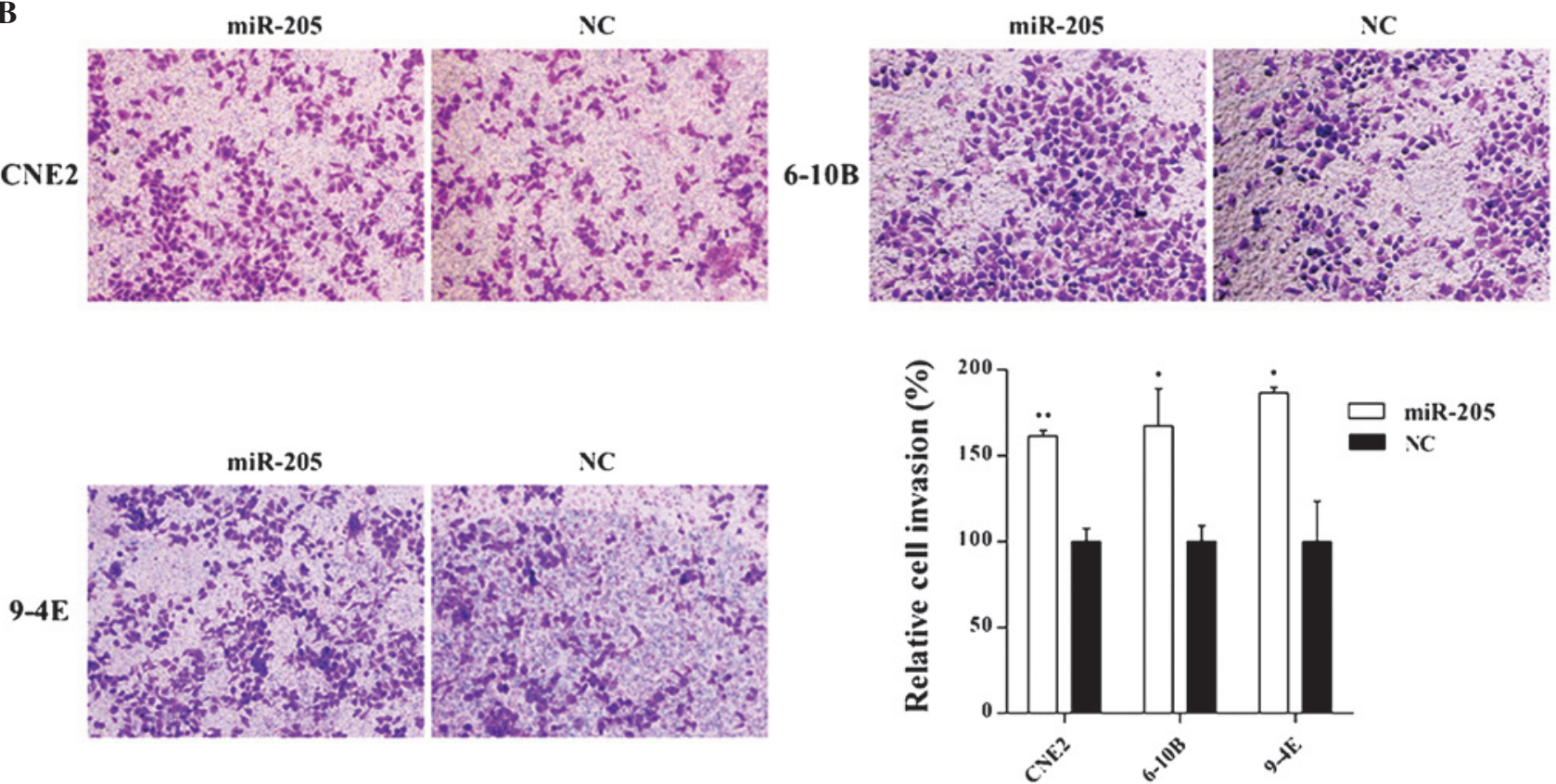

Figure 5. Effects of miR-205 on cell migration and invasion of NPC cells. (A) Cell migration was determined by a wound healing assay. The promotion rates of cell migration were $56.8 \%$ in $\mathrm{CNE} 2$ cells $(\mathrm{P}=0.003), 108.6 \%$ in $6-10 \mathrm{~B}$ cells $(\mathrm{P}=0.003)$ and $95.2 \%$ in $9-4 \mathrm{E}$ cells $(\mathrm{P}=0.004)$ after transfection with miR-205. (B) Cell invasion was determined by a Transwell assay. The number of invaded cells was increased in CNE2, 6-10B and 9-4E cells by $61.4 \%$ ( $\mathrm{P}=0.000), 67.4 \%$ $(\mathrm{P}=0.008)$ and $86.6 \%(\mathrm{P}=0.003)$, respectively, after transfection with miR-205. Cells are stained with crystal violet; magnification, $\mathrm{x} 10$. Values are expressed as the mean \pm standard deviation. ${ }^{*} \mathrm{P}<0.05 ;{ }^{* *} \mathrm{P}<0.001$ vs. NC. miR, microRNA; NC, negative control; NPC, nasopharyngeal carcinoma. 
A

miR-205

TP53INP1 WT 3'UTR

TP53INP1 MU 3'UTR

\author{
3'-GUCUGAGGCCACCUUACUUCCU-5' \\ | | | || | \\ 5'-UUGGAAACAAAAACAUGAAGGA - 3'
}

5'-UUGGAAACAAAAACCGTCCTTC -3'

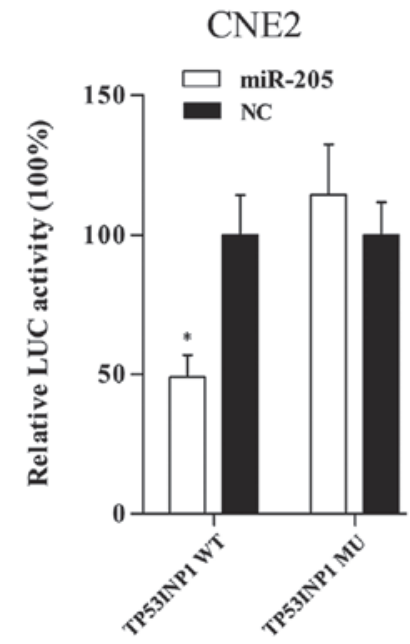

B

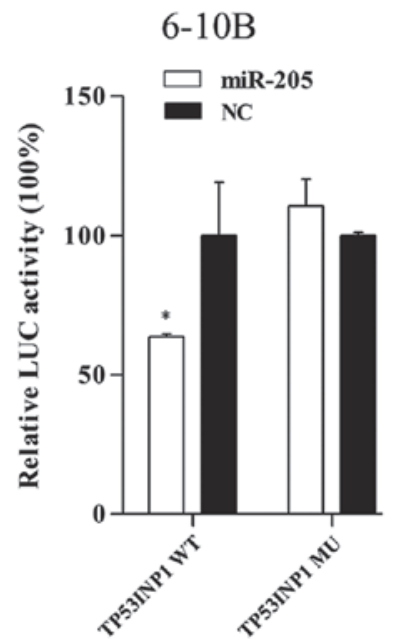

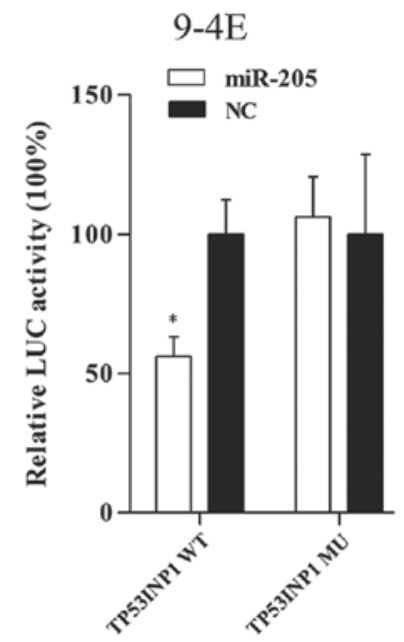

Figure 6. TP53IPN1 is a target gene of miR-205. (A) Fragments of TP53INP1 3'UTR, which contained the WT potential binding sites was synthesized and the MU fragments were generated by replacing $\mathrm{G}$ with $\mathrm{T}$ and $\mathrm{A}$ with $\mathrm{C}$ on the putative binding sites. (B) The target gene was verified by luciferase reporter assay. Co-transfection with miR-205 and TP53INP1-3'UTR significantly decreased the luciferase activity by 50.9\% (P=0.006), 36.4\% (P=0.03) and 43.9\% (P=0.006) in CNE2, 6-10B and 9-4E cells, respectively. However, the activity of the reporter containing the mutated seed sequence was not obviously changed. Values are expressed as the mean \pm standard deviation. "P<0.05 vs. NC. LUC, luciferase; WT, wild-type; Mut; mutant; UTR, untranslated region; miR, microRNA; NC, negative control; TP53INP1, tumor protein p53-inducible nuclear protein 1.

indicate that microRNAs have significant roles in regulating the expression of their targets genes, and influence cell biological behavior, including proliferation, motility and apoptosis (31-33). MiR-205 has opposite roles in various cancer types by serving as an oncogene or an anti-oncogene. Luo et al (34) found that miR-205 was upregulated in NPC biopsy specimens and correlated with the stage of NPC. Furthermore, Qu et al (35) demonstrated that overexpression of miR-205 reduced NPC-cell apoptosis. However, the function of miR-205 in NPC has remained elusive. The expression of miR-205 in NPC tissues was found to be upregulated in the present study. Furthermore, the present study investigated the role of miR-205 in NPC-derived cells and revealed that overexpression of miR-205 promoted NPC-cell proliferation, migration and invasion, and suppressed apoptosis, suggesting that miR-205 may act as an oncogene in NPC.

To shed further light on the tumor-promoting effect of miR-205 in NPC, the present study identified a target gene of miR-205, TP53INP1, via a bioinformatics target analysis. TP53INP1 is known to function depending on p53 and to promote apoptosis by phosphorylating Ser46 of p53 $(36,37)$. TP53INP1 encodes two protein isoforms which are able to modulate p53 activity to induce G1-arrest and enhance the p53-mediated apoptosis by coordinating with homeodomain-interacting protein kinase 2 , which binds to p53 and induces its phosphorylation in promyelocytic leukemia protein nuclear bodies $(38,39)$. In gastric cancer, it has been demonstrated that TP53INP1 accelerated cancer cell apoptosis and was closely associated with the progression and prognosis of gastric cancer (40). Furthermore, TP53INP1 was confirmed to be a target of several other miRNAs, which enhance the growth of several cancer types, including esophageal squamous cell carcinoma and breast cancer, cervical cancer (41-43). At the same time, TP53INP1 has been gradually considered to be a therapeutic target of certain cancer types $(44,45)$. In the present study, TP53INP1 was found to be a direct target of miR-205, suggesting that the effect of miR-205 on NPC may be partially mediated through this protein. However, the explicit function of TP53INP1 in NPC requires further verification.

In conclusion, the present study provided evidence that miR-205 has a pivotal role in NPC tumorigenesis, at least in part via TP53INP1, and may be utilized for the early detection and molecular-targeted therapy of NPC.

\section{Acknowledgements}

The present study was supported by the Science and Technology Development Fund Project of Shenzhen (grant nos. JCYJ20120827150357364 and JCYJ20130402114702127) and the Medical Research Project of the Health and Family Planning Commission of Shenzhen (grant no. 201302005).

\section{References}

1. Lu J, He ML, Wang L, Chen Y, Liu X, Dong Q, Chen YC, Peng Y, Yao KT, Kung HF and Li XP: MiR-26a inhibits cell growth and tumorigenesis of nasopharyngeal carcinoma through repression of EZH2. Cancer Res 71: 225-233, 2011.

2. Huang GL, Lu Y, Pu XX, He YX, Chen ML, Li YZ, Tang SY, Che $\mathrm{H}$ and $\mathrm{He} \mathrm{Z}$ : Association study between miR-149 gene polymorphism and nasopharyngeal carcinoma. Biomed Rep 1: 599-603, 2013.

3. McDermott AL, Dutt SN and Watkinson JC: The aetiology of nasopharyngeal carcinoma. Clin Otolaryngol Allied Sci 26: 82-92, 2001. 
4. Liu N, Jiang N, Guo R, Jiang W, He QM, Xu YF, Li YQ, Tang LL, Mao YP, Sun Y and Ma J: MiR-451 inhibits cell growth and invasion by targeting MIF and is associated with survival in nasopharyngeal carcinoma. Mol Cancer 12: 123, 2013.

5. Lai SZ, Li WF, Chen L, Luo W, Chen YY, Liu LZ, Sun Y, Lin AH, Liu MZ and Ma J: How does intensity-modulated radiotherapy versus conventional two-dimensional radiotherapy influence the treatment results in nasopharyngeal carcinoma patients? Int J Radiat Oncol Biol Phys 80: 661-668, 2011.

6. Bartel DP: MicroRNAs: Genomics, biogenesis, mechanism and function. Cell 116: 281-297, 2004

7. Cho HJ, Liu G, Jin SM, Parisiadou L, Xie C, Yu J, Sun L, Ma B, Ding J, Vancraenenbroeck R, et al: MicroRNA-205 regulates the expression of Parkinson's disease-related leucine-rich repeat kinase 2 protein. Hum Mol Genet 22: 608-620, 2013.

8. Ambros V: MicroRNA pathways in flies and worms: Growth, death, fat, stress and timing. Cell 113: 673-676, 2003.

9. Fabian MR, Sonenberg N and Filipowicz W: Regulation of mRNA translation and stability by microRNAs. Annu Rev Biochem 79: 351-379, 2010.

10. $\mathrm{Xu} \mathrm{Y,} \mathrm{Huang} \mathrm{Z} \mathrm{and} \mathrm{Liu} \mathrm{Y:} \mathrm{Reduced} \mathrm{miR-125a-5p} \mathrm{expression} \mathrm{is}$ associated with gastric carcinogenesis through the targeting of E2F3. Mol Med Rep 10: 2601-2608, 2014.

11. Zhou JJ, Zheng S, Sun LF and Zheng L: MicroRNA regulation network in colorectal cancer metastasis. World J Biol Chem 5 301-307, 2014

12. You J, Li Y, Fang N, Liu B, Zu L, Chang R, Li X and Zhou Q: MiR-132 suppresses the migration and invasion of lung cancer cells via targeting the EMT regulator ZEB2. PLoS One 9: e91827, 2014.

13. Yu Z, Ni L, Chen D, Zhang Q, Su Z, Wang Y, Yu W, Wu X, Ye J, Yang $\mathrm{S}$, et al: Identification of miR-7 as an oncogene in renal cell carcinoma. J Mol Histol 44: 669-677, 2013.

14. Li J, Li X, Kong X, Luo Q, Zhang J and Fang L: MiRNA-26b inhibits cellular proliferation by targeting CDK8 in breast cancer. Int J Clin Exp Med 7: 558-565, 2014.

15. Lu R, Ji Z, Li X, Zhai Q, Zhao C, Jiang Z, Zhang S, Nie L and Yu Z: MiR-145 functions as tumor suppressor and targets two oncogenes, ANGPT2 and NEDD9, in renal cell carcinoma. J Cancer Res Clin Oncol 140: 387-397, 2014.

16. Wang Y, Li J, Tong L, Zhang J, Zhai A, Xu K, Wei L and Chu M The prognostic value of miR-21 and miR-155 in non-small-cell lung cancer: A meta-analysis. Jpn J Clin Oncol 43: 813-820, 2013.

17. Xue Q, Sun K, Deng HJ, Lei ST, Dong JQ and Li GX: MicroRNA-338-3p inhibits colorectal carcinoma cell invasion and migration by targeting smoothened. Jpn J Clin Oncol 44: 13-21, 2014.

18. Huang GL, Lu Y, Pu XX, He YX, Chen ML, Li YZ, Tang SY, Che $\mathrm{H}$ and $\mathrm{He} \mathrm{Z}$ : Association study between miR-149 gene polymorphism and nasopharyngeal carcinoma. Biomed Rep 1: 599-603, 2013

19. Huang GL, Chen ML, Li YZ, Lu Y, Pu XX, He YX, Tang SY, Che H, Zou Y, Ding C and He Z: Association of miR-146a gene polymorphism with risk of nasopharyngeal carcinoma in the central-southern Chinese population. J Hum Genet 59: 141-144, 2014.

20. Zhu X, Wang Y, Sun Y, Zheng J and Zhu D: MiR-155 up-regulation by LMP1 DNA contributes to increased nasopharyngeal carcinoma cell proliferation and migration. Eur Arch Otorhinolaryngol 271: 1939-1945, 2014

21. Lyu X, Fang W, Cai L, Zheng H, Ye Y, Zhang L, Li J, Peng H, Cho WC, Wang E, et al: TGFßR2 is a major target of miR-93 in nasopharyngeal carcinoma aggressiveness. Mol Cancer 13: 51, 2014

22. Liu Y, Li Z, Wu L, Wang Z, Wang X, Yu Y, Zhao Q and Luo F: MiRNA-125a-5p: A regulator and predictor of gefitinib's effect on nasopharyngeal carcinoma. Cancer Cell Int 14: 24, 2014.

23. Wang Z, Liao H, Deng Z, Yang P, Du N, Zhanng Y and Ren H: MiRNA-205 affects infiltration and metastasis of breast cancer. Biochem Biophys Res Commun 441: 139-143, 2013.

24. Kalogirou C, Spahn M, Krebs M, Joniau S, Lerut E, Burger M, Scholz CJ, Kneitz S, Riedmiller H and Kneitz B: MiR-205 is progressively down-regulated in lymph node metastasis but fails as a prognostic biomarker in high-risk prostate cancer. Int J Mol Sci 14: 21414-21434, 2013.

25. Tian L, Zhang J, Ge J, Xiao H, Lu J, Fu S, Liu M and Sun Y: MicroRNA-205 suppresses proliferation and promotes apoptosis in laryngeal squamous cell carcinoma. Med Oncol 31: 785, 2014
26. Su N, Qiu H, Chen Y, Yang T, Yan Q and Wan X: MiR-205 promotes tumor proliferation and invasion through targeting ESRRG in endometrial carcinoma. Oncol Rep 29: 2297-2302, 2013.

27. Gottardo F, Liu CG, Ferracin M, Calin GA, Fassan M, Bassi P, Sevignani C, Byrne D, Negrini M, Pagano F, et al: Micro-RNA profiling in kidney and bladder cancers. Urol Oncol 25: 387-392, 2007.

28. Cui M, Xiao Z, Sun B, Wang Y, Zheng M, Ye L and Zhang X: Involvement of cholesterol in hepatitis B virus $X$ protein-induced abnormal lipid metabolism of hepatoma cells via up-regulating miR-205-targeted ACSL4. Biochem Biophys Res Commun 445: 651-655, 2014.

29. Sun Y, Mao YP, Ma J, Huang Y, Tang LL, Wang Y, Liu LZ and Lu TX: Influences of magnetic resonance imaging on the staging system of nasopharyngeal carcinoma. Ai Zheng 26: 158-163, 2007.

30. Livak KJ and Schmittgen TD: Analysis of relative gene expression data using real-time quantitative PCR and the 2(-Delta Delta C(T)) method. Methods 25: 402-408, 2001.

31. Liu Y, Yang K, Sun X, Fang P, Shi H, Xu J, Xie M and Li M: MiR-138 suppresses airway smooth muscle cell proliferation through the PI3K/AKT signaling pathway by targeting PDK1. Exp Lung Res: Jul 7, 2015 (Epub ahead of print).

32. Li R, Shi X, Ling F, Wang C, Liu J, Wang W and Li M: MiR-34a suppresses ovarian cancer proliferation and motility by targeting AXL. Tumor Biol: Apr 21, 2015 (Epub ahead of print).

33. Chen JJ, Liu SX, Chen MZ and Zhao ZY: Has-miR-125a and $125 \mathrm{~b}$ are induced by treatment with cisplatin in nasopharyngeal carcinoma and inhibit apoptosis in a p53-dependent manner by targeting p53 mRNA. Mol Med Rep 12: 3569-3594, 2015.

34. Luo Z, Zhang L, Li Z, Li X, Li G, Yu H, Jiang C, Dai Y, Guo X, Xiang $\mathrm{J}$ and $\mathrm{Li} \mathrm{G}$ : An in silico analysis of dynamic changes in microRNA expression profiles in stepwise development of nasopharyngeal carcinoma. BMC Med Genomics 5: 3, 2012

35. Qu C, Liang Z, Huang J, Zhao R, Su C, Wang S, Wang X, Zhang R, Lee MH and Yang H: MiR-205 determines the radioresistance of human nasopharyngeal carcinoma by directly targeting PTEN. Cell cycle 11: 785-796, 2012.

36. Tomasini R, Samir AA, Pebusque MJ, Calvo EL, Totaro S, Dagorn JC, Dusetti NJ and Iovanna JL: P53-dependent expression of the stress-induced protein (SIP). Eur J Cell Biol 81: 294-301, 2002.

37. Okamura S, Arakawa H, Tanaka T, Nakanishi H, Ng CC, Taya Y, Monden M and Nakamura Y: p53DINP1, a p53-inducible gene, regulates p53-dependent apoptosis. Mol Cell 8: 85-94, 2001.

38. Tomasini R, Samir AA, Carrier A, Isnardon D, Cecchinelli B, Soddu S, Malissen B, Dagorn JC, Iovanna JL and Dusetti NJ: TP53INP1s and homeodomain-interacting protein kinase-2 (HIPK2) are partners in regulating p53 activity. J Biol Chem 278: 37722-37729, 2003.

39. D'Orazi G, Cecchinelli B, Bruno T, Manni I, Higashimoto Y, Saito S, Gostissa M, Coen S, Marchetti A, Del Sal G, et al: Homeodomain-interacting protein kinase-2 phosphorylates p53 at Ser 46 and mediates apoptosis. Nat Cell Biol 4: 11-19, 2002.

40. Jiang PH, Motoo Y, Garcia S, Iovanna JL, Pébusque MJ and Sawabu N: Down-expression of tumor protein 553 -induced nuclear protein 1 in human gastric cancer. World J Gastroenterol 12: 691-696, 2006

41. Zhang J, Cheng C, Yuan X, He JT, Pan QH and Sun FY: microRNA-155 acts as an oncogene by targeting the tumor protein 53-induced nuclear protein 1 in esophageal squamous cell carcinoma. Int J Clin Exp Pathol 7: 602-610, 2014.

42. Zhang CM, Zhao J and Deng HY: MiR-155 promotes proliferation of human breast cancer MCF-7 cells through targeting tumor protein 53-induced nuclear protein 1. J Biomed Sci 20: 79, 2013.

43. Wei Q, Li YX, Liu M, Li X and Tang H: MiR-17-5p targets TP53INP1 and regulates cell proliferation and apoptosis of cervical cancer cells. IUBMB Life 64: 697-704, 2012

44. Shahbazi J, Lock R and Liu T: Tumor protein 53-induced nuclear protein 1 enhances p53 function and represses tumorigenesis. Front Genet 4: 80, 2013.

45. Giusiano S, Baylot V, Andrieu C, Fazli L, Gleave M, Iovanna JL, Taranger-Charpin C, Garcia S and Rocchi P: TP53INP1 as new therapeutic target in castration-resistant prostate cancer. Prostate 72: 1286-1294, 2012. 